\title{
Análise de espécies bacterianas em telefones públicos do centro da cidade de Caruaru - PE
}

\author{
Analysis of bacterial species in public telephones in the city center of Caruaru - PE \\ Jeonara Mirelly Nascimento Ferreira ${ }^{1}$, Nélia Cíntia da Costa e Silva ${ }^{1}$, Walkyria Almeida Santana ${ }^{2}$, Charles \\ Lindberg Barcia Nascimento Duarte ${ }^{3}$ Andréa Kedima Diniz Cavalcanti Tenório ${ }^{4}$, Fábio Correia Sampaio ${ }^{5}$, \\ Pedro Pereira Tenório ${ }^{*}$
}

${ }^{1}$ Graduação em Biomedicina, Associação Caruaruense de Ensino Superior (ASCES), Biomédica do Laboratório de Análises Clínicas Cintra, Pernambuco; ${ }^{2}$ Graduação em Biomedicina e Mestre em Ciências Biológicas, UFPE, Professora Assistente II, ASCES; ${ }^{3}$ Acadêmico de Medicina, Universidade Federal do Vale do São Francisco (UNIVASF); ${ }^{4}$ Graduação em Enfermagem, ASCES-UNITA, Mestranda em Ciências da Saúde e Biológicas, UNIVASF; ${ }^{5}$ Graduação em Química e Odontologia, UFPB, Mestrado em Odontologia, Universidade Federal Fluminense (UFF), Doutor em Cariologia, Universidade de Oslo, Noruega, Professor Titular, UFPB ${ }^{6}$ Graduação em Biomedicina, ASCES, Mestre em Patologia, UFPE, Doutor em Biologia Aplicada à Saúde, UFPE, Professor Assistente, UNIVASF

\begin{abstract}
Resumo
Introdução: os aparelhos de telefones públicos representam importantes agentes disseminadores de infecções por se tratarem de objetos frequentemente manipulados por grande número de pessoas em trânsito das mais diversas regiões. Considerando que a pele humana contém uma microbiota típica e a manipulação de objetos pode propiciar o deslocamento de microrganismos, os aparelhos de telefone podem transmitir doenças através desses agentes. Objetivo: analisar a variedade de espécies bacterianas nos fones de ouvido dos aparelhos de telefones públicos localizados no centro da cidade de Caruaru-PE (Brasil). Metodologia: foram coletados esfregaços dos fones de ouvido, especificamente da região auricular, de 77 telefones públicos do centro da cidade de Caruaru. 0 material foi colhido com swab estéril e transportado em meio BHI ao Laboratório de Práticas da Saúde da Associação Caruaruense de Ensino Superior, onde foram realizadas cultura e identificação dos agentes bacterianos. Resultados: em todas as amostras foram encontradas bactérias, havendo um predomínio de Staphylococcus coagulase negativa (50,64\%), seguido de Bacillus subtilis (27,27\%), como também houve presença de Bacillus sp. $(28,57)$, Staphylococcus aureus $(18,18 \%)$, Enterococcus sp. $(2,59)$, Streptococus do grupo viridans $(1,29)$ e Streptococus sp. $(1,29)$. Conclusão: Há grande diversidade de espécies bacterianas nos fones de ouvido dos telefones públicos do Centro de Caruaru.
\end{abstract}

Palavras - chave: Análise Bacteriana. Telefones. Infecções.

\begin{abstract}
Introduction: public telephones represent important dissemination agents because they are objects varied by large numbers of people in transit from the most diverse regions. Consider that a human skin contains a typical microbiota and a manipulation of objects can propitiate the displacement of microorganisms, telephone devices can transmit diseases through agents. Objective: To analyze a variety of bacterial species in the headsets of public telephone sets located in the city of Caruaru-PE (Brazil). Methods: Smears were collected from the earphones, specifically from the auricular region, from 77 public telephones in the city center of Caruaru. The material was collected with sterile swab and transported in BHI medium to the Laboratory of Health Practices of the Caruaruense Association of Higher Education, where culture and identification of bacterial agents were carried out. Results: Staphylococcus coagulase negative (50.64\%), followed by Bacillus subtilis (27.27\%), were also found in all samples, as well as the presence of Bacillus sp. $(28,57)$, Staphylococcus aureus $(18.18 \%)$, Enterococcus sp. $(2,59)$, Streptococus do grupo viridans $(1,29)$ and Streptococus sp. $(1,29)$. Conclusion: There is a great diversity of bacterial species in the headsets of the public telephones of the Center of Caruaru. Keywords: Bacterial Analysis. Phones. Infections.
\end{abstract}

\section{INTRODUÇÃO}

A pele humana alberga naturalmente alguns microrganismos, que compõem a chamada microbiota residente, constituída por elementos que se reproduzem e se mantém em harmonia com as defesas do hospedeiro. Porém a manipulação de objetos pode facilitar o deslocamento

Correspondente/Corresponding: *Pedro Pereira Tenório-End: Rua Félix Benzota de Carvalho, 16. Ap:101. Paulo Afonso-BA - Tel: (81) 987927851 - E-mail: pedrotenorio28@gmail.com de microrganismos provenientes de fontes exógenas, que podem colonizar temporariamente os extratos mais superficiais da pele e causar doenças ${ }^{1}$.

Os objetos inanimados são um importante meio de transmissão de patógenos entre seres humanos ${ }^{2}$. Nesse contexto, pode-se destacar os aparelhos telefônicos, que podem ser um local propício a contaminação e proliferação de microrganismos, seu uso pode funcionar como um evento contribuinte na dispersão de doenças contagiosas ${ }^{3}$. 
Logo após a sua invenção, em 1876 o aparelho telefônico tornou-se um meio de comunicação largamente empregado. Porém, desde o começo do século XX já se discutia sobre a possibilidade de os aparelhos telefônicos atuarem como potenciais fômites na transmissão de doenças infecciosas ${ }^{4}$.

Certos patógenos envolvidos em doenças graves, como o pneumococo, já foram isolados em grandes proporções em aparelhos telefônicos. Estudos feitos em laboratório mostraram que o Staphylococcus aureus e o Streptococcus pyogenes inoculados de maneira experimental foram capazes de sobreviver por vários dias nos telefones ${ }^{5}$.

Telefones públicos podem ser utilizados diariamente por um grande número de pessoas, que entram em contato direto com os aparelhos. Por meio desse contato os indivíduos podem transmitir microrganismos para os telefones, fazendo com que estes se tornem depósitos de patógenos e fonte de infecção para os próximos usuários ${ }^{6}$.

Avaliações feitas através de culturas de secreção acumulada em aparelhos telefônicos demonstraram que o fone de ouvido é a área do telefone com maior contaminação bacteriana, atingindo $158 \mathrm{ufc} / \mathrm{cm}^{2}$, seguida pelo bocal $\left(102,6 \mathrm{ufc} / \mathrm{cm}^{2}\right)$ e teclado $\left(36,6 \mathrm{ufc} / \mathrm{cm}^{2}\right)^{7}$.

A presença de determinados microrganismos em telefones públicos pode indicar condições higiênico-sanitárias insatisfatórias, podendo ainda representar importante meio de transmissão de possíveis patologias ${ }^{8}$.

O objetivo do presente estudo foi verificar a possível contaminação bacteriana nos fones de ouvido dos telefones públicos do centro da cidade de Caruaru, tendo em vista se tratar de um bairro de elevado trânsito de pessoas de diversas classes sociais e diferentes graus de instrução, no que diz respeito aos corretos hábitos de higiene.

\section{METODOLOGIA}

Para a realização do estudo foram realizadas coletas de esfregaços dos fones de ouvido de 77 telefones públicos do centro da cidade de Caruaru - PE. O programa utilizado para o cálculo da amostra, com o intuito de se obter resultados com significância estatística, foi feito por meio do programa estatística SampleXS for Windows. Para o cálculo, foi considerado o total de telefones públicos do centro da cidade de Caruaru (85 telefones). Foi padronizado a prevalência com estimativa de $50 \%$, com erro máximo de $5 \%$ e efeito de delineamento igual a 1 . Assim, um número mínimo de 77 telefones públicos foi estabelecido para que o grau de confiança dos resultados obtidos fosse de cerca de $95 \%$.

A coleta das amostras foi realizada com a utilização de luvas e swab estéreis, sendo obtidos esfregaços da parte que entra em contato com o pavilhão auricular (fone de ouvido) quando se utiliza o telefone. Após coletados, os esfregaços foram imediatamente colocados em tubos de ensaio estéreis contendo meio de cultura de enriquecimento de infusão de cérebro e coração (BHI) e encaminhados ao Laboratório de Práticas da Saúde da Associação Caruaruense de Ensino Superior.

Os tubos de ensaio foram incubados a $36^{\circ} \mathrm{C}$ por 24 horas e após este período a amostra foi semeada em placas de Petri contendo ágar sangue de carneiro a $5 \%$. As placas foram incubadas a $36^{\circ} \mathrm{C}$ por 24 horas e as colônias microbianas crescidas após este período foram identificadas através de provas bioquímicas. Para a identificação dos gêneros e espécies bacterianas foi utilizada a coloração de Gram e foram feitos os testes de catalase, coagulase, DNAse, $\mathrm{NaCl} 6,5 \%$, bile esculina e hemólise. As placas foram incubadas a $36^{\circ} \mathrm{C}$ por 24 horas e as amostras foram analisadas qualitativamente.

\section{RESULTADOS}

Em todos os telefones públicos onde as amostras foram coletadas, houve isolamento de espécies bacterianas. Todas as cepas bacterianas identificadas pertencem ao grupo das bactérias Gram-positivas, as quais estão apresentadas na tabela 1.

Tabela 1 - Espécies bacterianas isoladas nos telefones públicos estudados

\begin{tabular}{lcc}
\hline Espécies bacterianas & $\begin{array}{c}\text { Numero de aparelhos } \\
\text { telefônicos }\end{array}$ & \% do total \\
\hline Staphylococcus coagulase negativa & 39 & 50,64 \\
Bacillu subtilis & 21 & 27,27 \\
Bacillus sp. & 22 & 28,57 \\
Staphylococcus aureus & 14 & 18,18 \\
Enterocossus sp. & 2 & 2,59 \\
Streptococus do grupo viridans & 1 & 1,29 \\
Streptococus sp & 1 & 1,29 \\
\hline TOTAL & 77 & 100 \\
\hline
\end{tabular}

Fonte: Autor

Vários aparelhos telefônicos apresentaram mais de uma espécie bacteriana. A espécie mais encontrada foi o Staphylococcus coagulase negativa seguida de Bacillus sp. , como também houve presença de Staphylococcus aureus. A figura 1 demonstra as porcentagens das espécies isoladas dos aparelhos telefônicos.

Figura 1 - Porcentagens das espécies isoladas

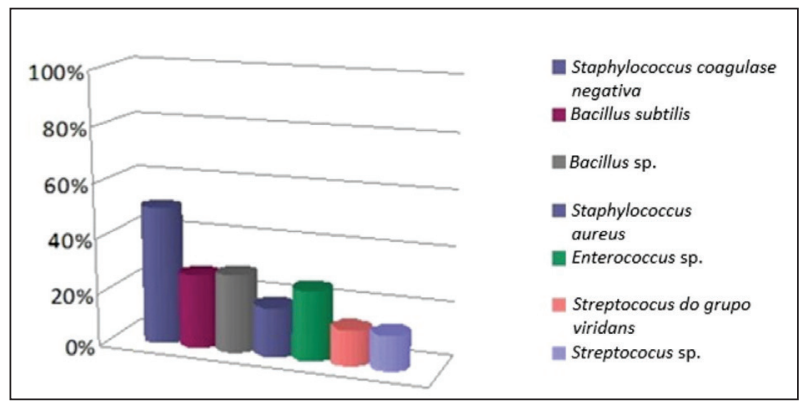

Fonte: Autor 


\section{DISCUSSÃO}

Estudos com o objetivo de verificar as condições higiênico-sanitárias em amostras, tais como leite, água, areia de praia, desinfetantes de uso domiciliar, de manipuladores de alimentos, de serviço de alimentação hospitalar, de lactários e de equipamentos utilizados em radiologia odontológica, têm sido realizados por vários autores no mundo ${ }^{8}$. Diante deste fato, a presente pesquisa vem somar dados a esses estudos.

Em um estudo conduzido na cidade de Marília - SP, semelhante a este, Person e colaboradore ${ }^{4}$ realizaram coletas de fone de ouvido de telefones públicos isolando as seguintes espécies bacterianas: Staphylococcus coagulase negativa, Staphylococcus aureus, Corynebacterium sp, Enterococcus faecalis, Enterobacter aglomerans, Bacillus sp.

Os resultados do presente estudo mostraram que as espécies bacterianas em sua maioria Gram-positivas, podem estar presentes em superfícies dos fones de ouvido de aparelhos de telefones públicos. Além disso, bactérias típicas da microbiota da pele também habitam os aparelhos telefônicos, tendo em vista que a maioria dos aparelhos apresentaram cepas de Staphylococcus coagulase negativa e algumas de Staphylococcus aureus.

Os Staphylococcus coagulase negativa estão associados às bacteremias hospitalares em diferentes situações: septicemias neonatais, pacientes imunodeprimidos, uso de nutrição parenteral total, pacientes pós-cirúrgicos e uso de dispositivos intravasculares ${ }^{9}$.

Um estudo realizado em uma escola americana mostrou que o número de bactérias presentes em telefones públicos escolares é maior no período vespertino em comparação com o período matutino, sendo que a maioria dos patógenos isolados não apresentava risco sério à saúde dos estudantes que usaram os telefones públicos ${ }^{10}$.

Coutinho et $a{ }^{11}$ realizaram um estudo isolando filamentos fúngicos em telefones públicos, onde verificou que por falta de manutenção ou limpeza inadequada dos telefones públicos, os microrganismos presentes podem vir a provocar danos à saúde, uma vez que esses aparelhos são utilizados por pessoas de diferentes classes sociais e hábitos variados, tanto pessoas sadias quanto imunocomprometidas.

Carvalho et al. ${ }^{7}$ verificaram a contaminação dos aparelhos telefônicos públicos na cidade do Rio de Janeiro e propuseram que o formato do áudio seja modificado, visando à redução da contaminação por microrganismos, além da criação de uma legislação que formalize a responsabilidade de limpeza dos aparelhos e oriente as prestadoras de serviço de telefonia quanto à necessidade de afastar os equipamentos das instalações sanitárias ou emprego de aparelhos que não requeiram o contato direto dos usuários.

\section{CONCLUSÃO}

A partir do presente estudo, concluiu-se que há uma grande variedade de espécies bacterianas encontradas nos telefones públicos presentes no centro da cidade de Caruaru, bairro de elevado trânsito de pessoas de diversas classes sociais e diferentes graus de instrução, no que diz respeito aos corretos hábitos de higiene e onde há uma grande concentração de empresas do ramo do comércio, como por exemplo, restaurantes, bares, lanchonetes, hospitais e laboratórios. Tal pesquisa alerta para a necessidade de outros estudos de verificação de contaminação ambiental e de fômites como prováveis veículos de transmissão de doenças.

\section{REFERÊNCIAS}

1. SANTOS, A. A. M. Higienização das mãos no controle das infecções em serviços da saúde. Disponível em: <http://www.anvisa.gov.br/servicosaude/controle/higienizacao_mao.pdf.> Acesso em: 22 mar. 2017.

2. SATTAR, A.S. et al. Determination of the activity of an alcohol-based hand gel against human adeno-, rhino-, and rotaviruses using the fingerpad method. Infect. Control Hosp. Epidemiol., New Jersey, v. 21, p. $516-519,2000$.

3. AKINYEMI, K. O. et al. The potential role of mobile phones in the spread of bacterial infections. J. Infect. Dev. Ctries, Sassari, v. 3, n. 8, p. 628-632, 2009.

4. PERSON, O. C. et al. Avaliação da flora bacteriana dos fones de ouvido de telefones públicos e hospitalares de Marília. Arq. Med. ABC., Santo André, v. 30, n. 1, p. 34-38, 2005.

5. WHITE, D. A. Are telephones an infeccion hazard? Br. med. j., London, v.280, n.6215, p. 696-697, 1980.

6. MARTINS, C. H. G. et. al. Contaminação de telefones públicos em França, São Paulo, Brasil. Rev. bras. Ci. Saúde., São Paulo, v. 12, n. 2, p.127-136, 2008.

7. CARVALHO, C. A. et al. Contaminação microbiana de aparelhos telefônicos públicos e risco de saúde dos usuários. J. bras. med., Rio de Janeiro, v. 82, n. 6, p. 34B-34H, 2002.

8. ALVES, C. F. V. et al. Condições higiênico-sanitárias de telefones públicos no município de Santos. Rev. News Lab., São Paulo, v.82, p.192-200, 2007.

9. RAAD, I. et al. Impact of central venous catheter removal on the recurrence of catheter-related coagulase-negative staphylococcal bacteremia. Infect. control hosp. epidemiol., New Jersey, v.13, p.215-221, 1992.

10. YALOWITZ, M.; BROOK, I. The recovery of bacteria from the handpiece of a high school telephone. J. environ health., Denver, v. 65, n. 6, p.18-20, 2003.

11. COUTINHO, F. P. et al. Isolation of filamentous fungi from public telephones of the metropolitan region of the city of Recife, PE, Brazil. Braz. j. microbiol., São Paulo, v. 38, p. 324-329, 2007. 